\title{
Portafolio
}





\section{Te veo desde mi ventana}

\section{Estefanía Penny Lanfranco}

El interés sobre la fotografía me ha llevado a los objetos y las atmósferas. Estoy atraída por la posibilidad de que, en la creación de una imagen, lo inerte sea capaz suscitar sensaciones.

En ese proceso de búsqueda visual, descubrí que el espacio íntimo (una habitación o el hogar) nos enmarca. Exalta nuestras luces y también nuestras sombras. Determina, cual encuadre fotográfico, lo que queremos o lo que no a estamos dispuestos a mostrar. Nos refleja; es un espejo de lo vivido: de los recuerdos, gustos y sensibilidad.

En el retrato, tan importante como el sujeto es el segundo plano; el entorno que inscribe al personaje en un universo y construye qué hay detrás de un rostro, obra o profesión.

Así es como la cámara, en esta serie fotográfica, se vuelve pretexto y vehículo para ingresar a los recintos de una selección de creadores peruanos consumados.

Aquellos que dedicaron su vida al desarrollo de universos narrativos, poéticos o dramáticos, ahora permiten que el lente construya los suyos.

En "Te veo desde mi ventana" (2015-2019) me valgo de la cámara analógica, de la atmósfera del espacio íntimo y de la casa como objeto, para reflejarlos y enmarcarlos en un retrato de ellos y de mí misma. 



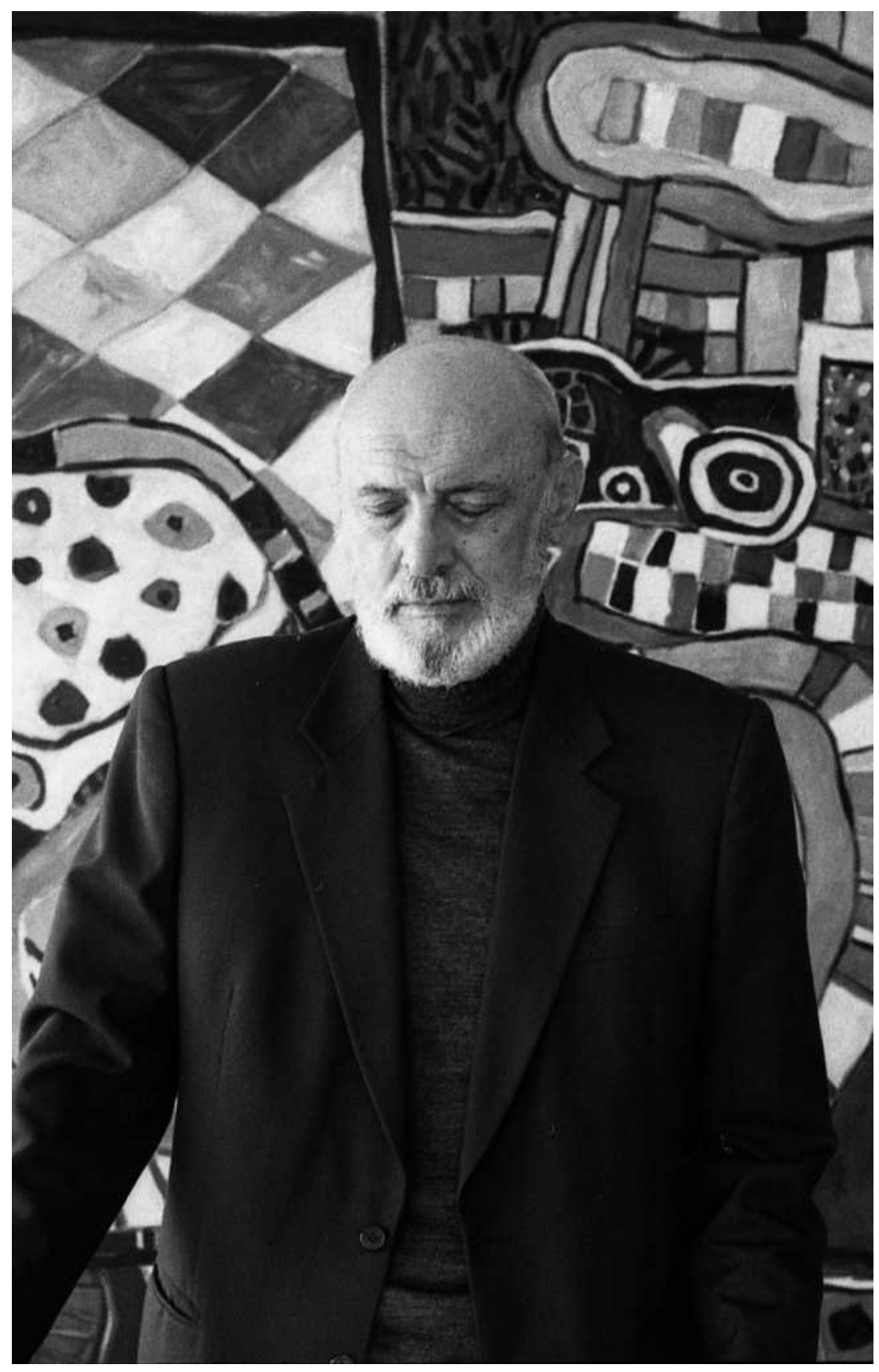

Fernando Ampuero 


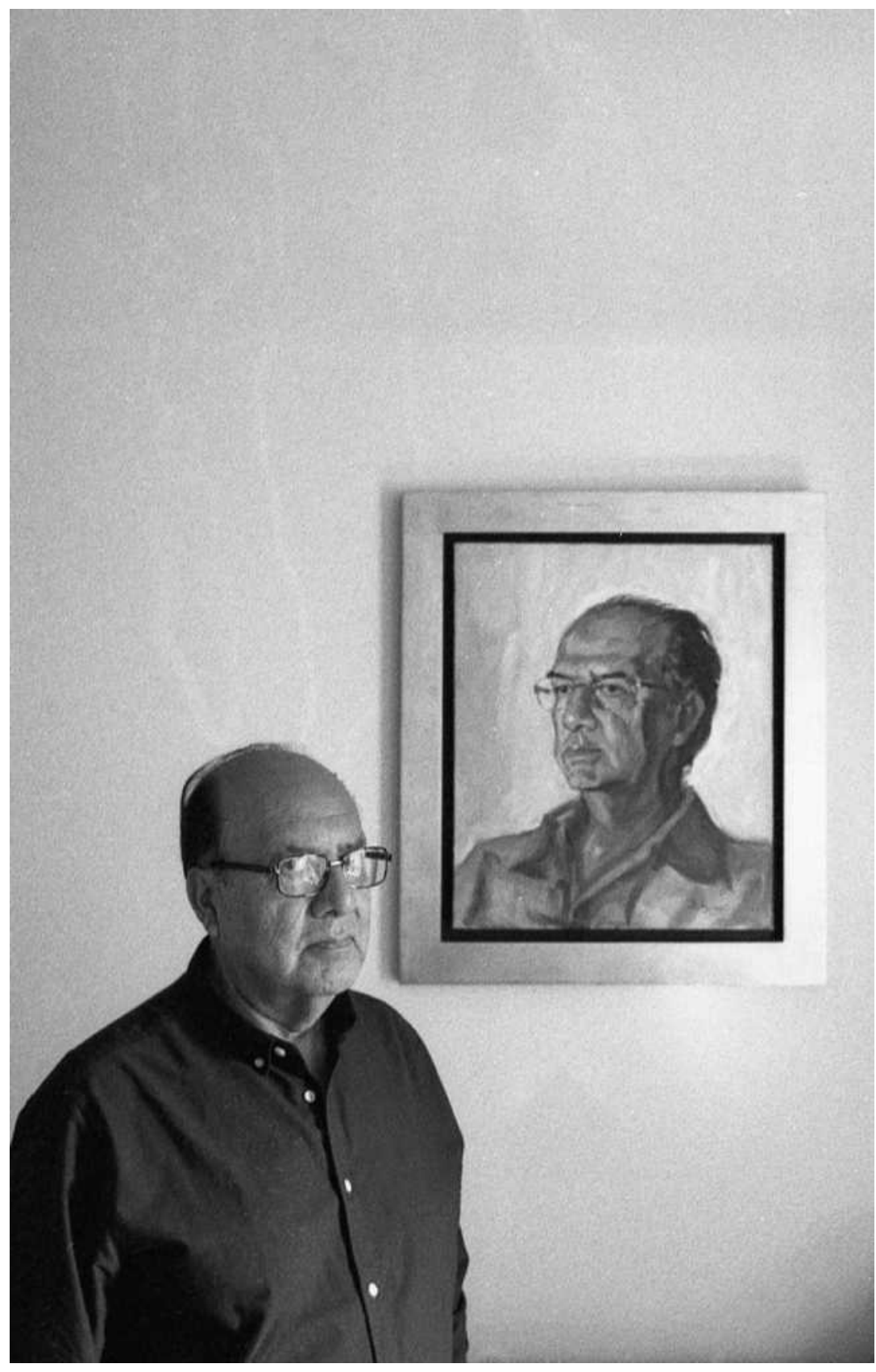

Roberto Reyes Tarazona 


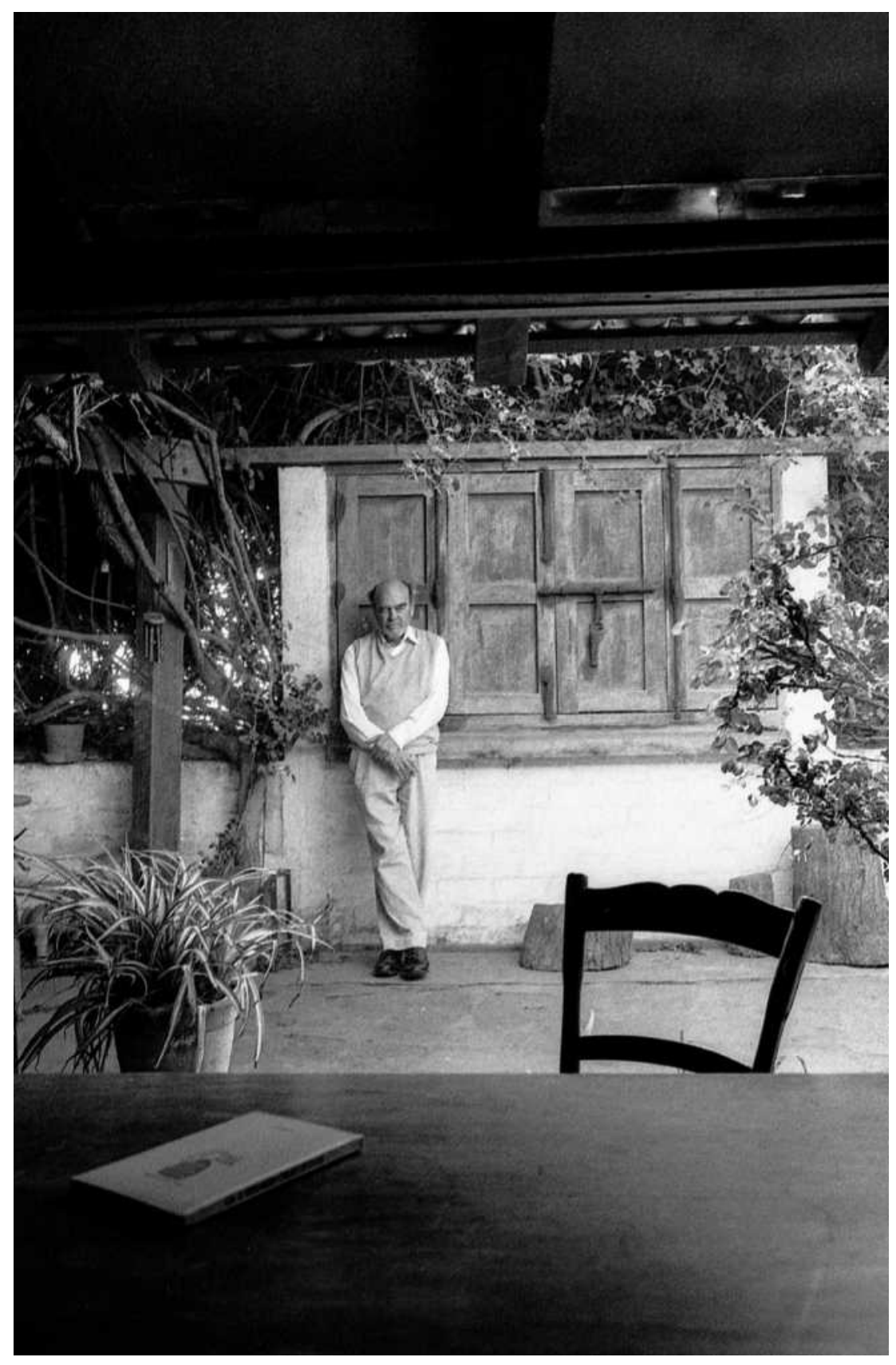

Luis Jochamovitz 


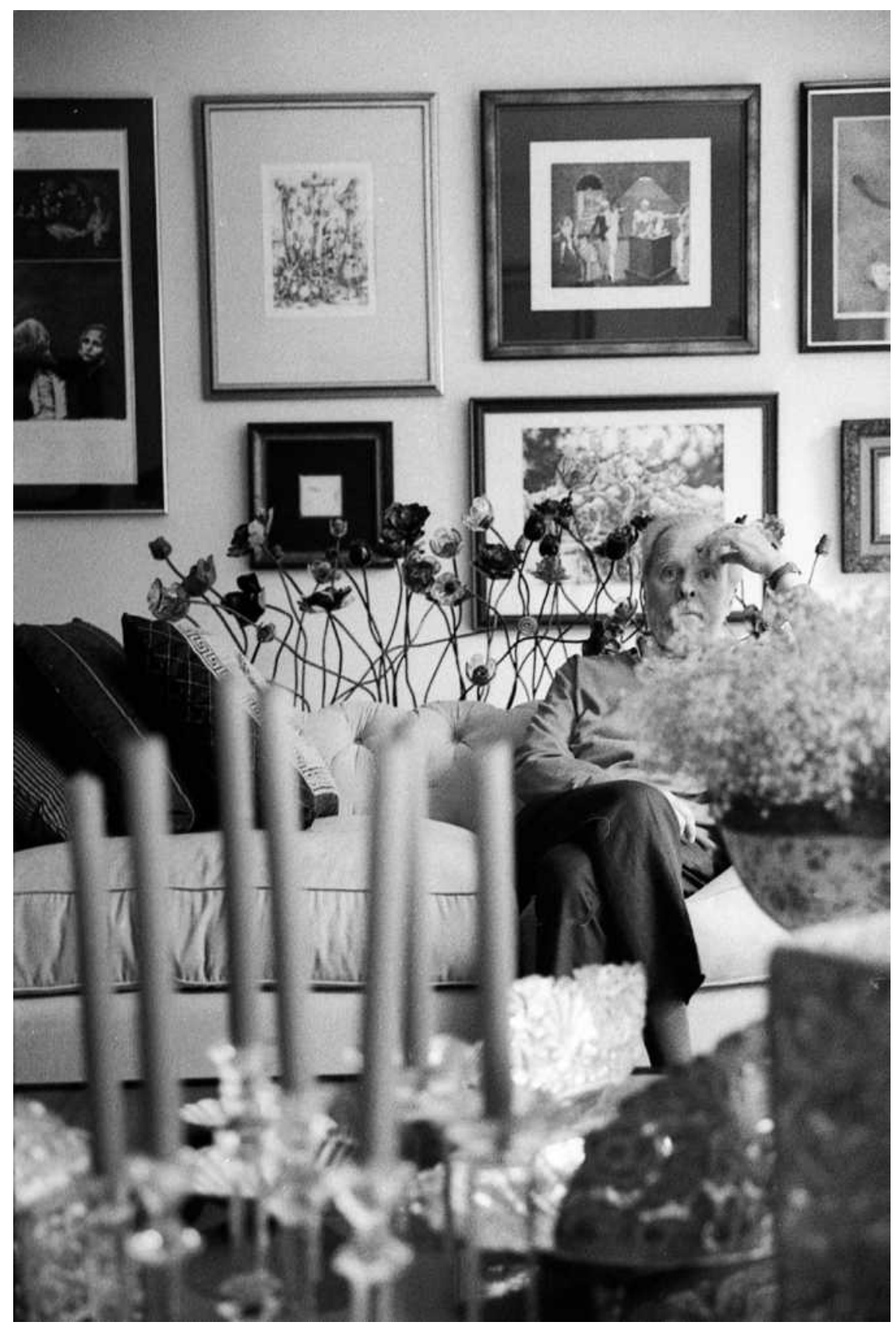

Harry Belevan 


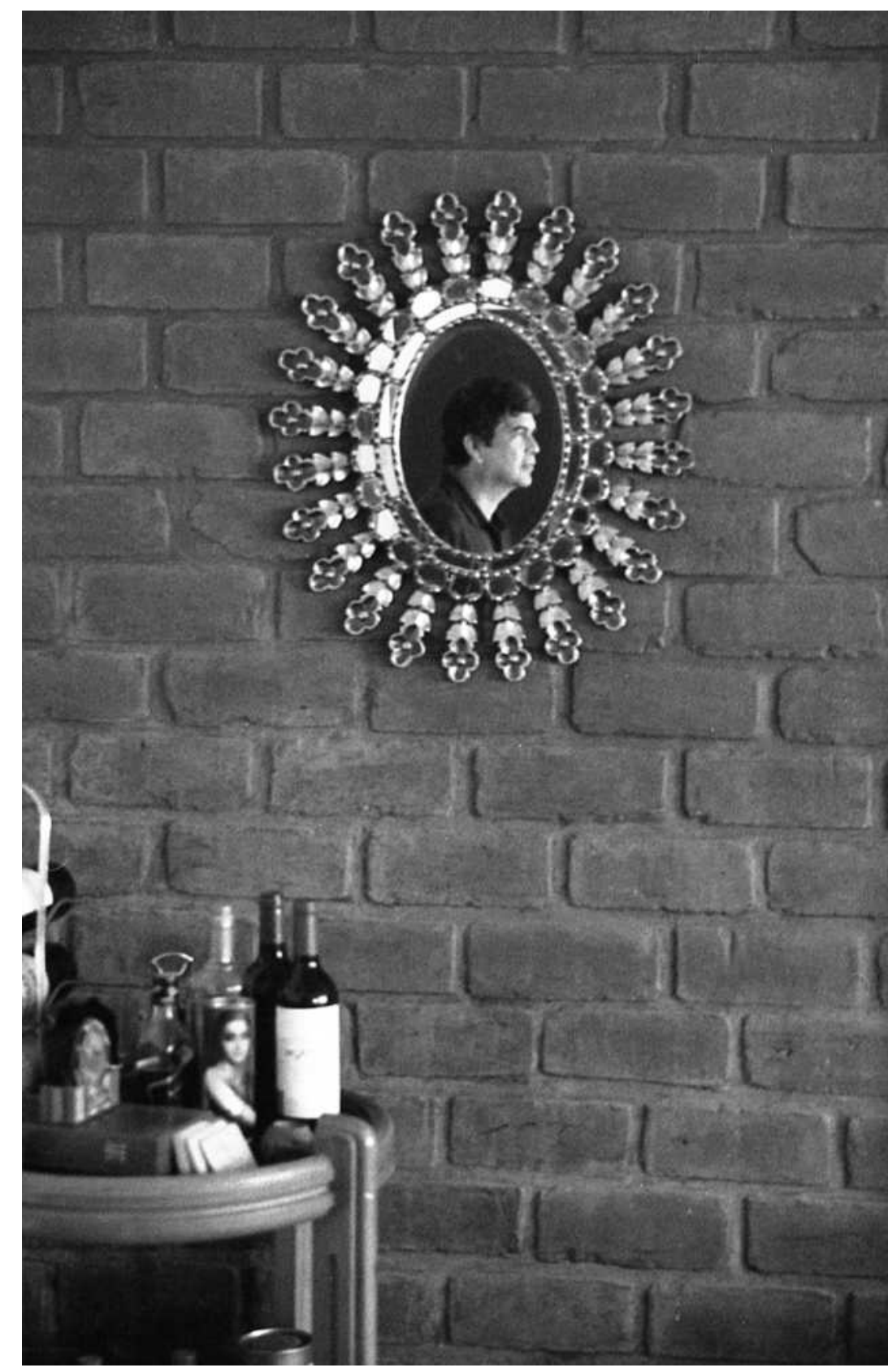

José Güich 


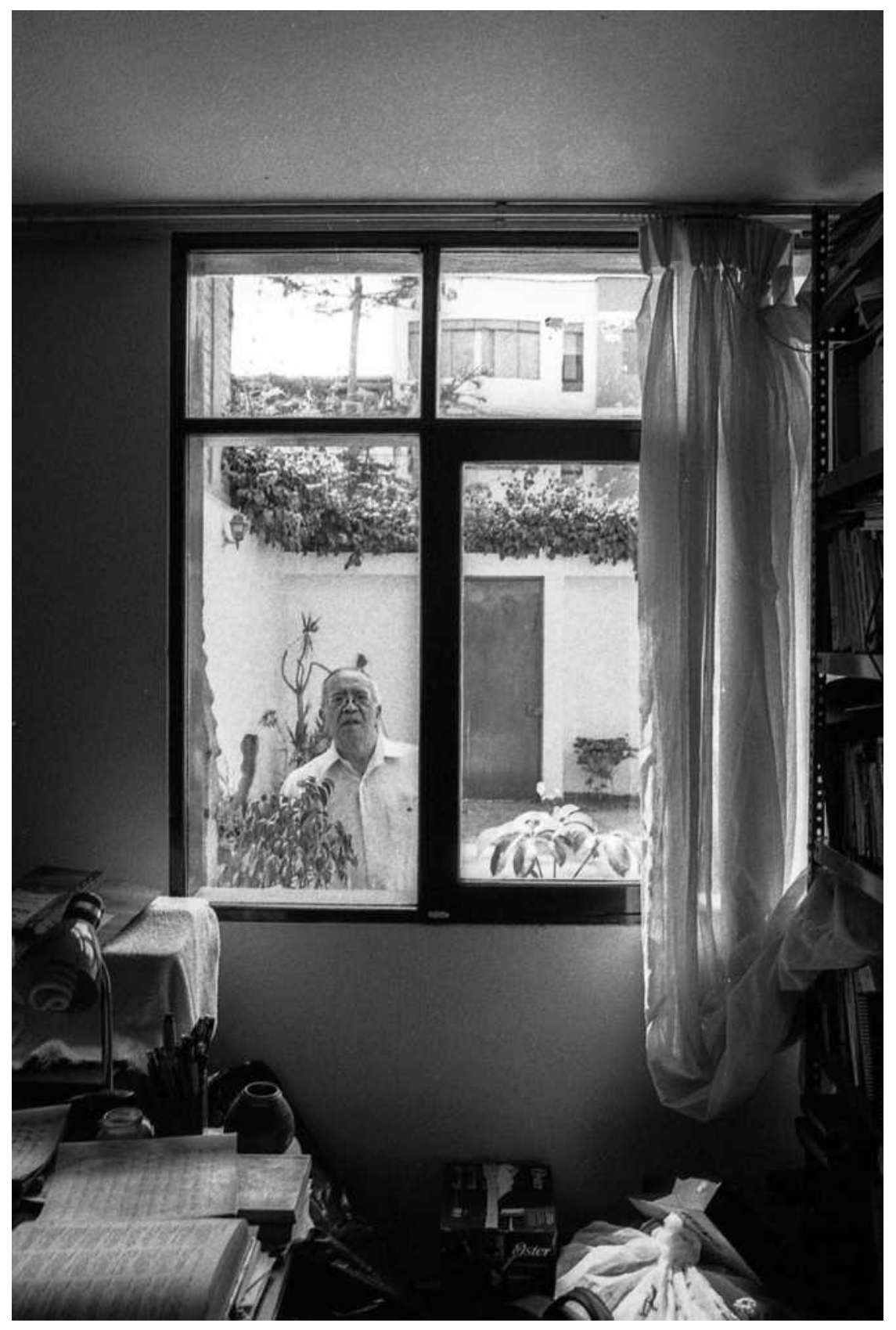

Augusto Higa 


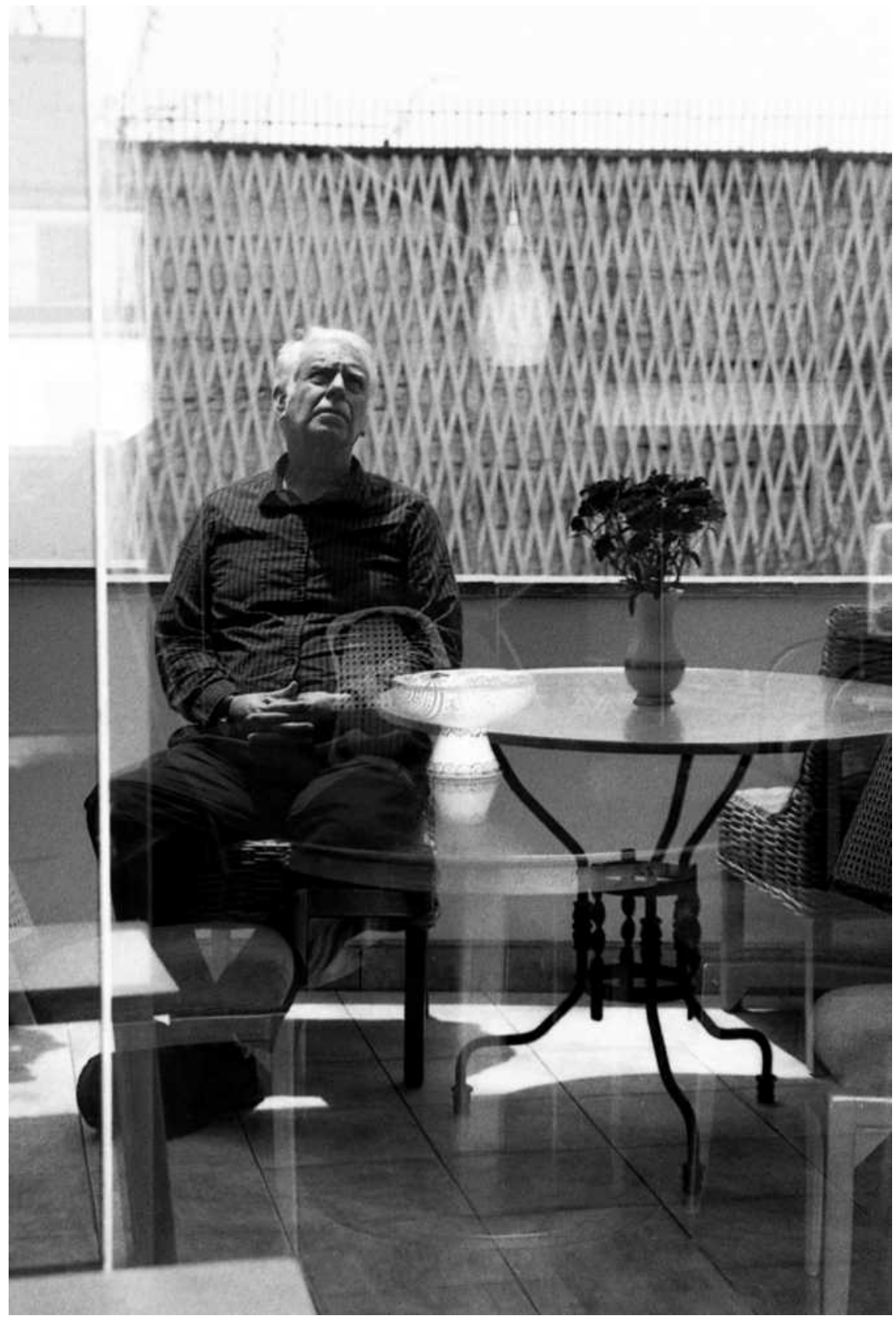

Alonso Cueto 


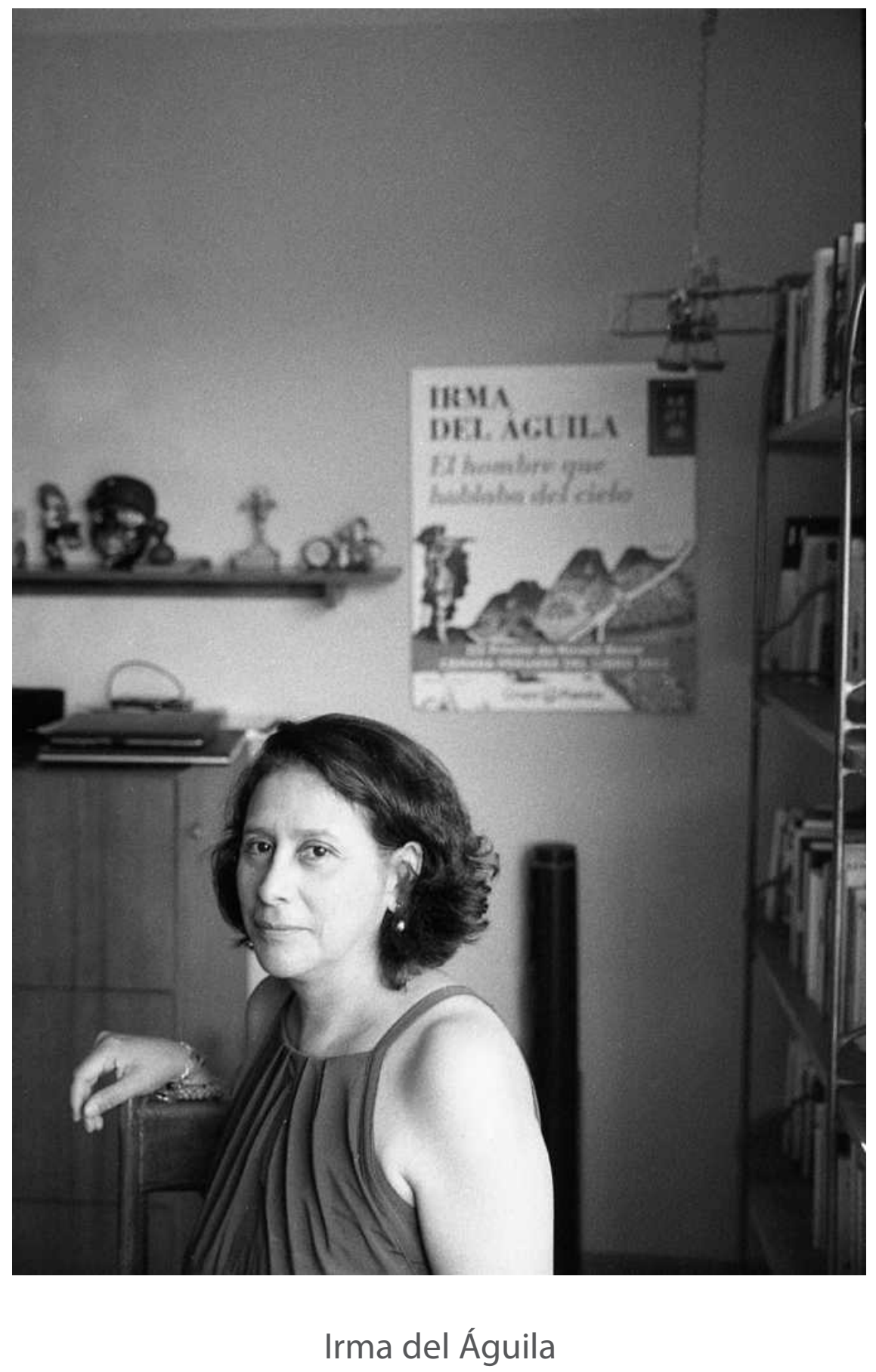




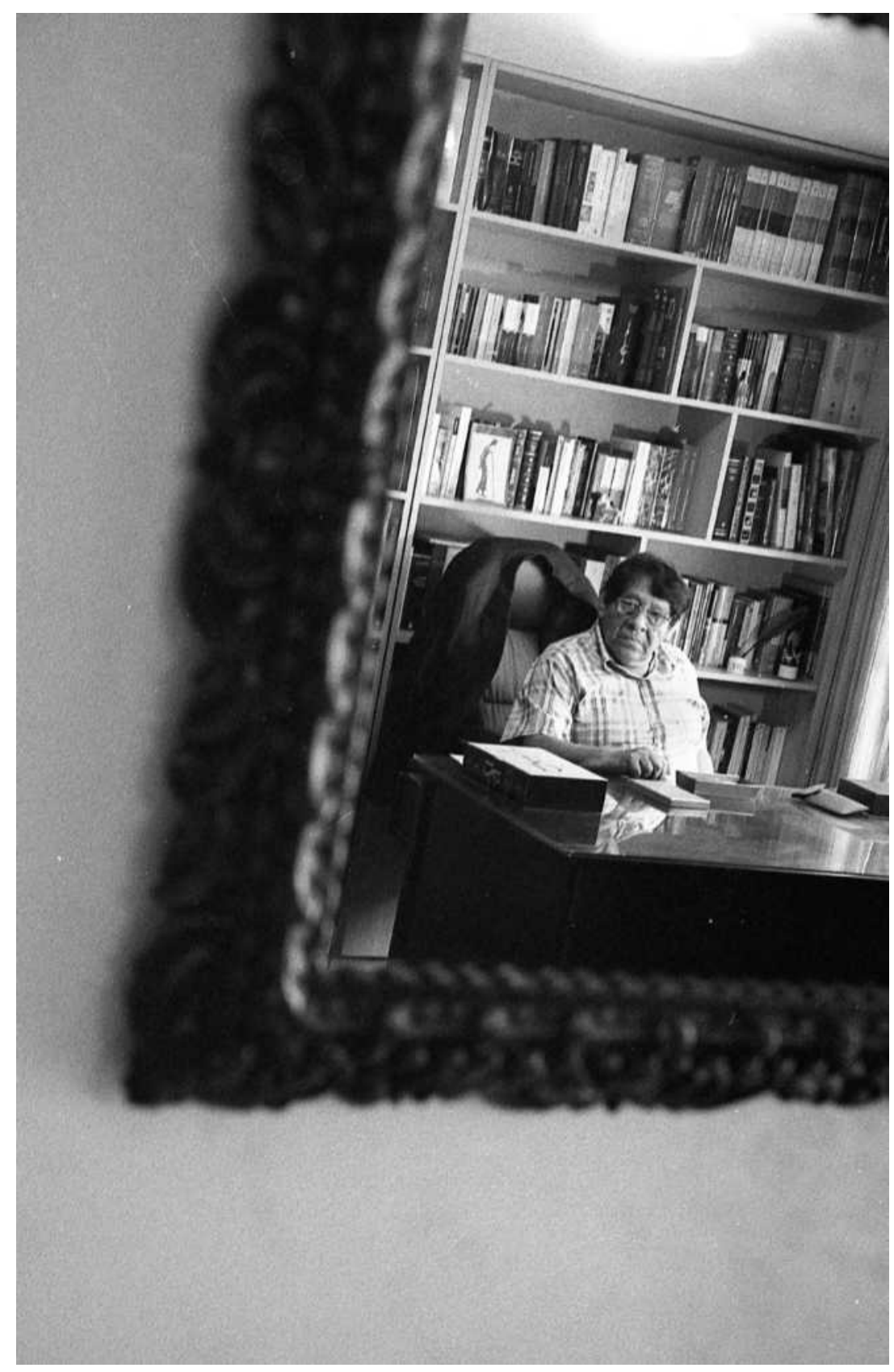

Antonio Gálvez Ronceros 


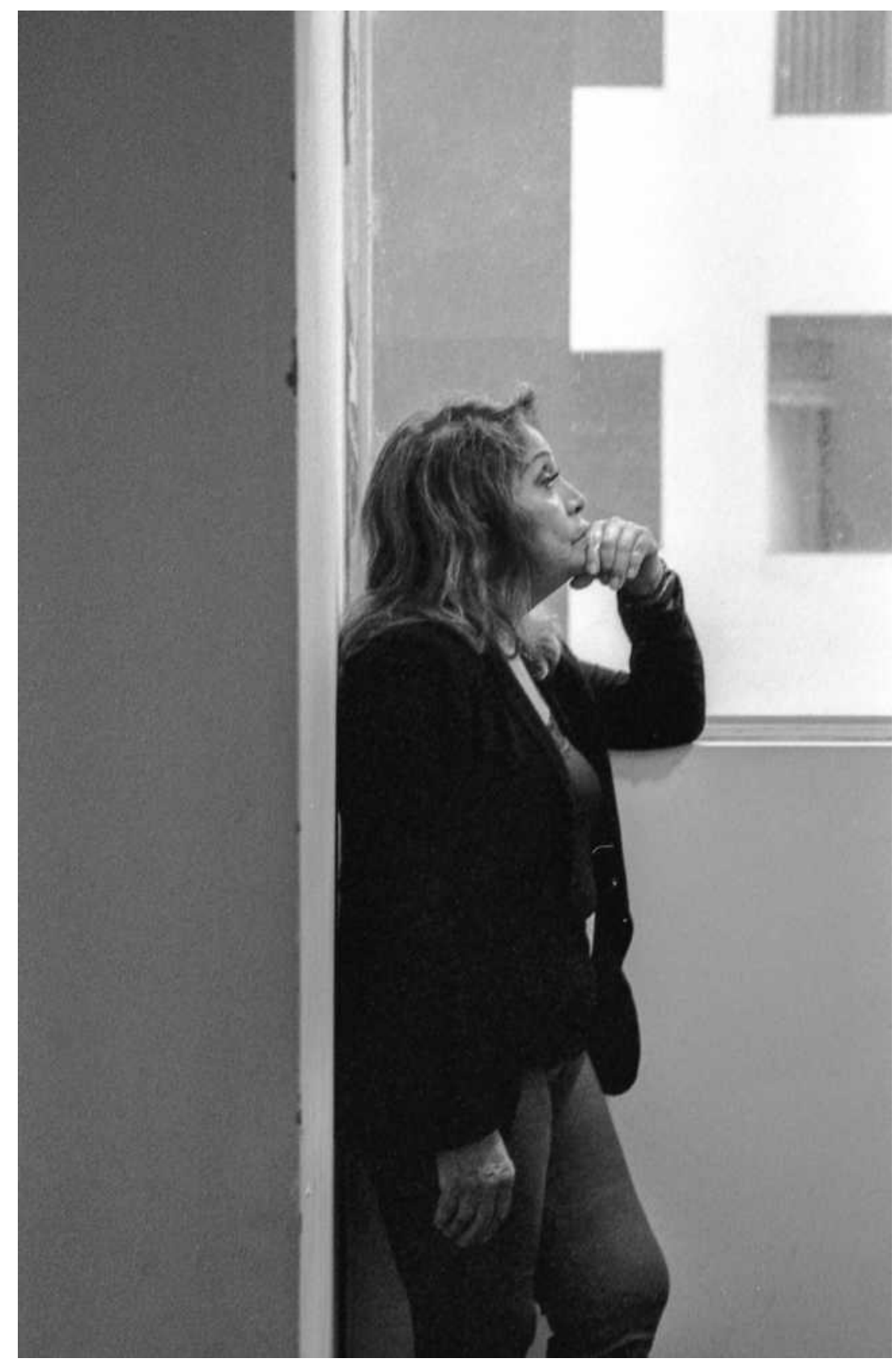

Elizabeth Salazar 


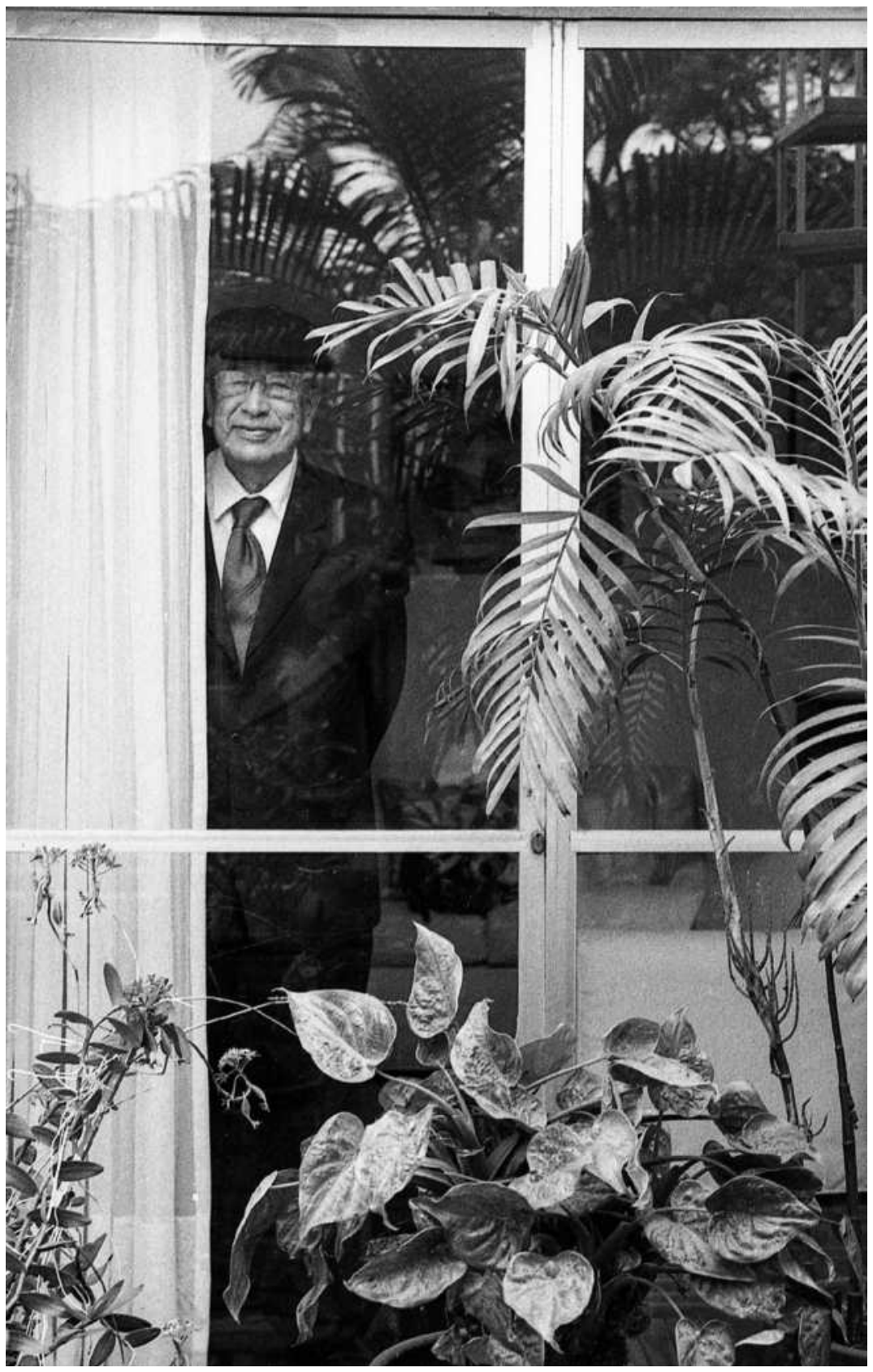

Marco Martos 


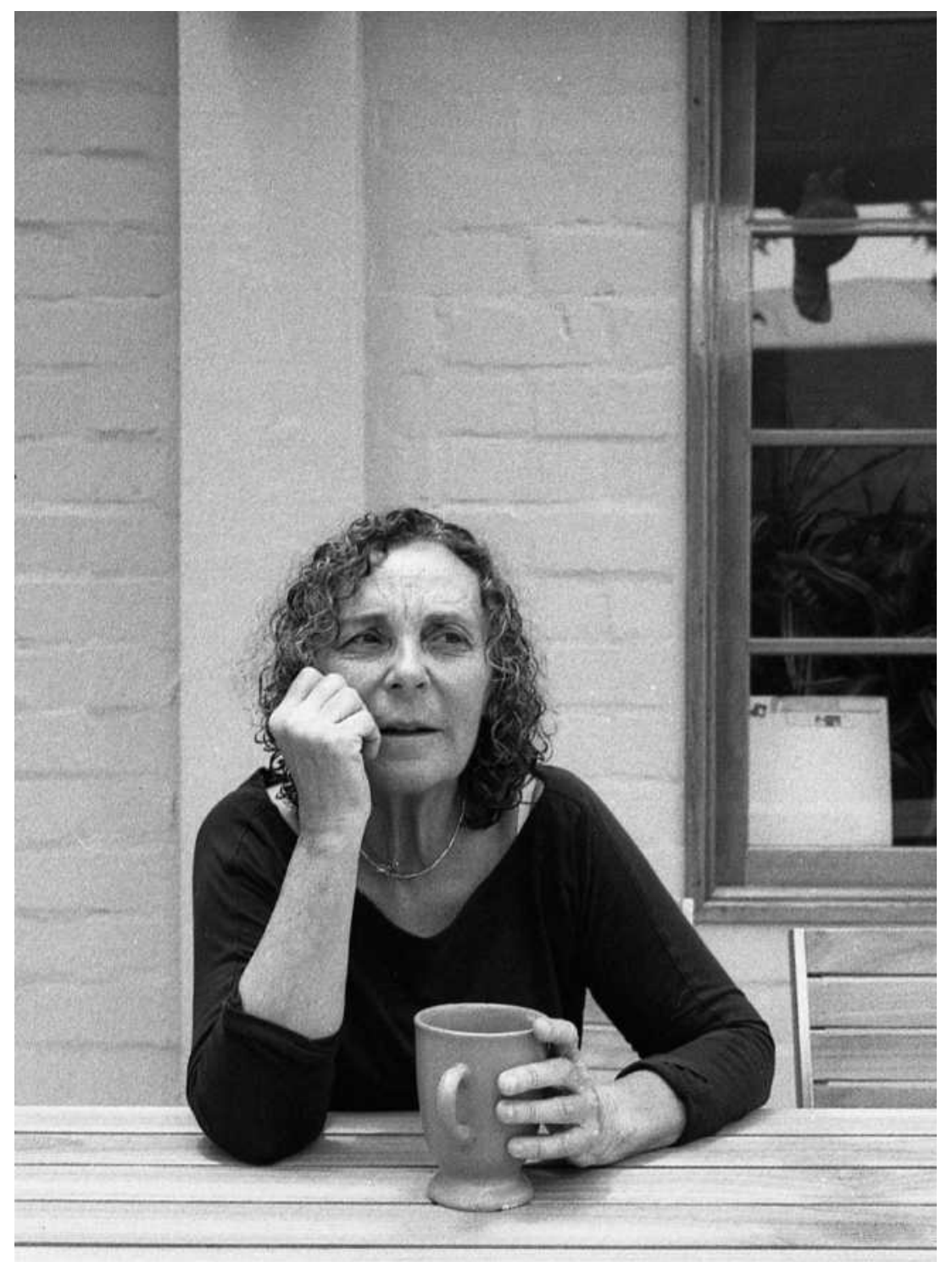




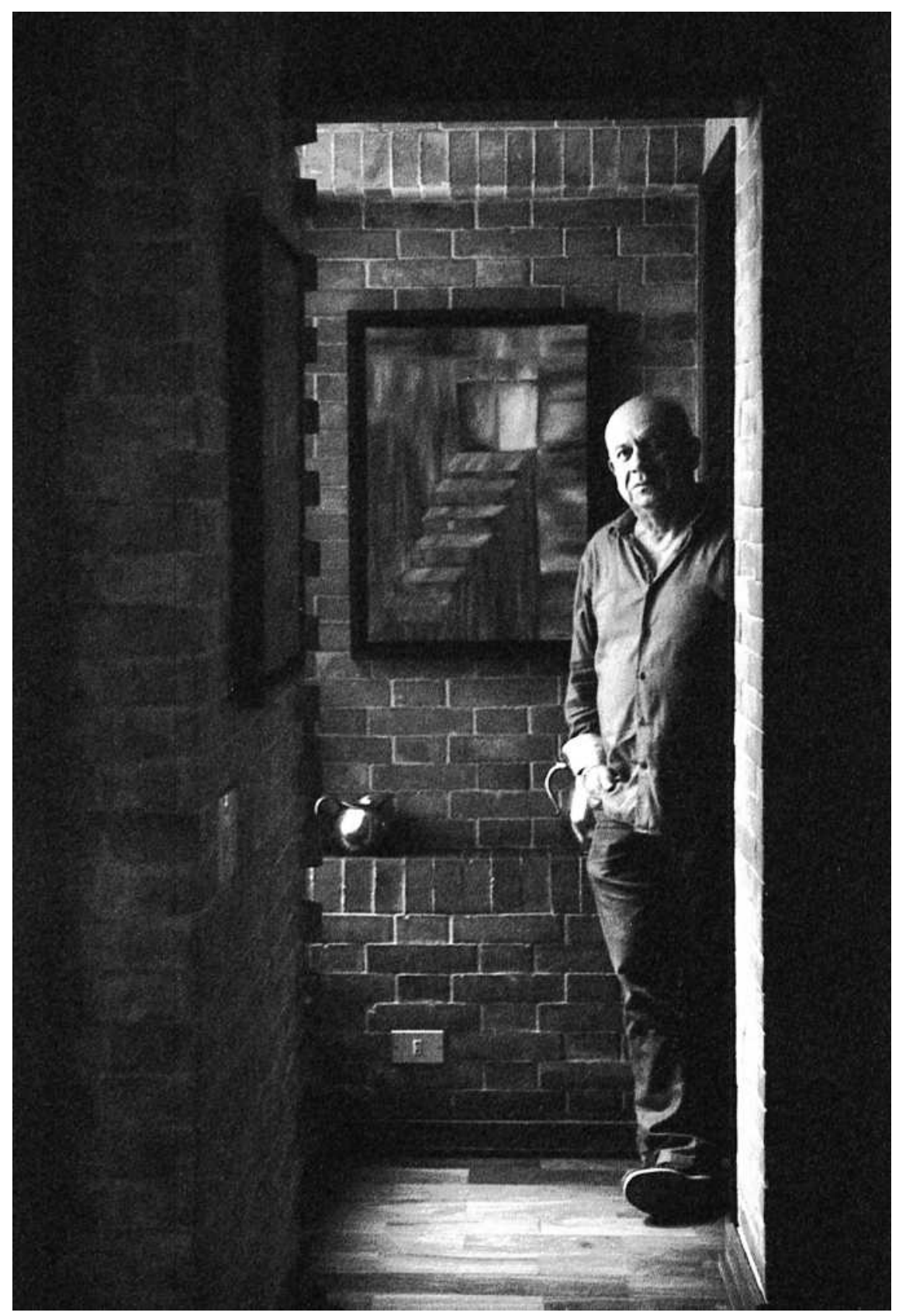

Carlos López Degregori 

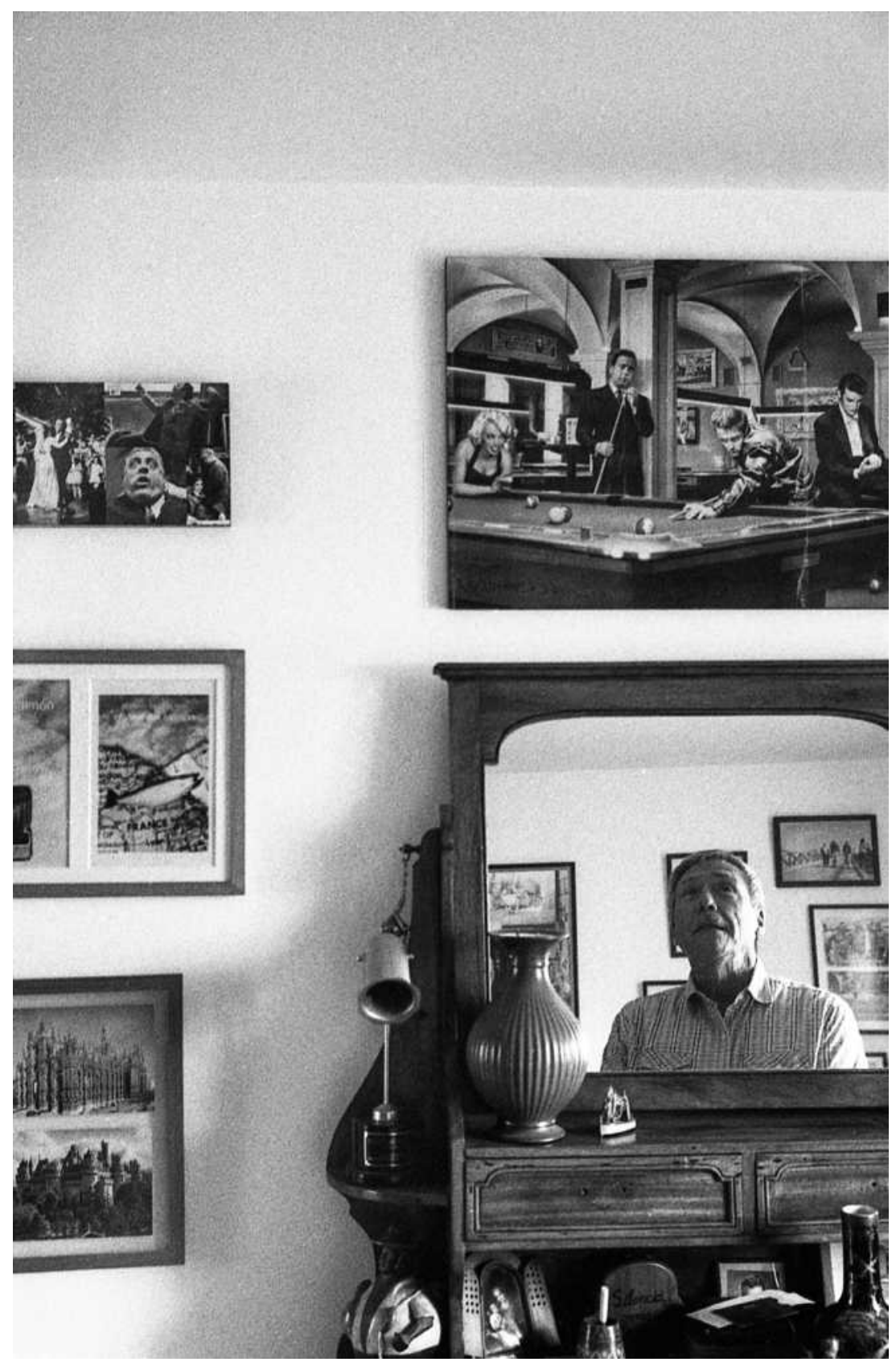

Abelardo Sánchez León 


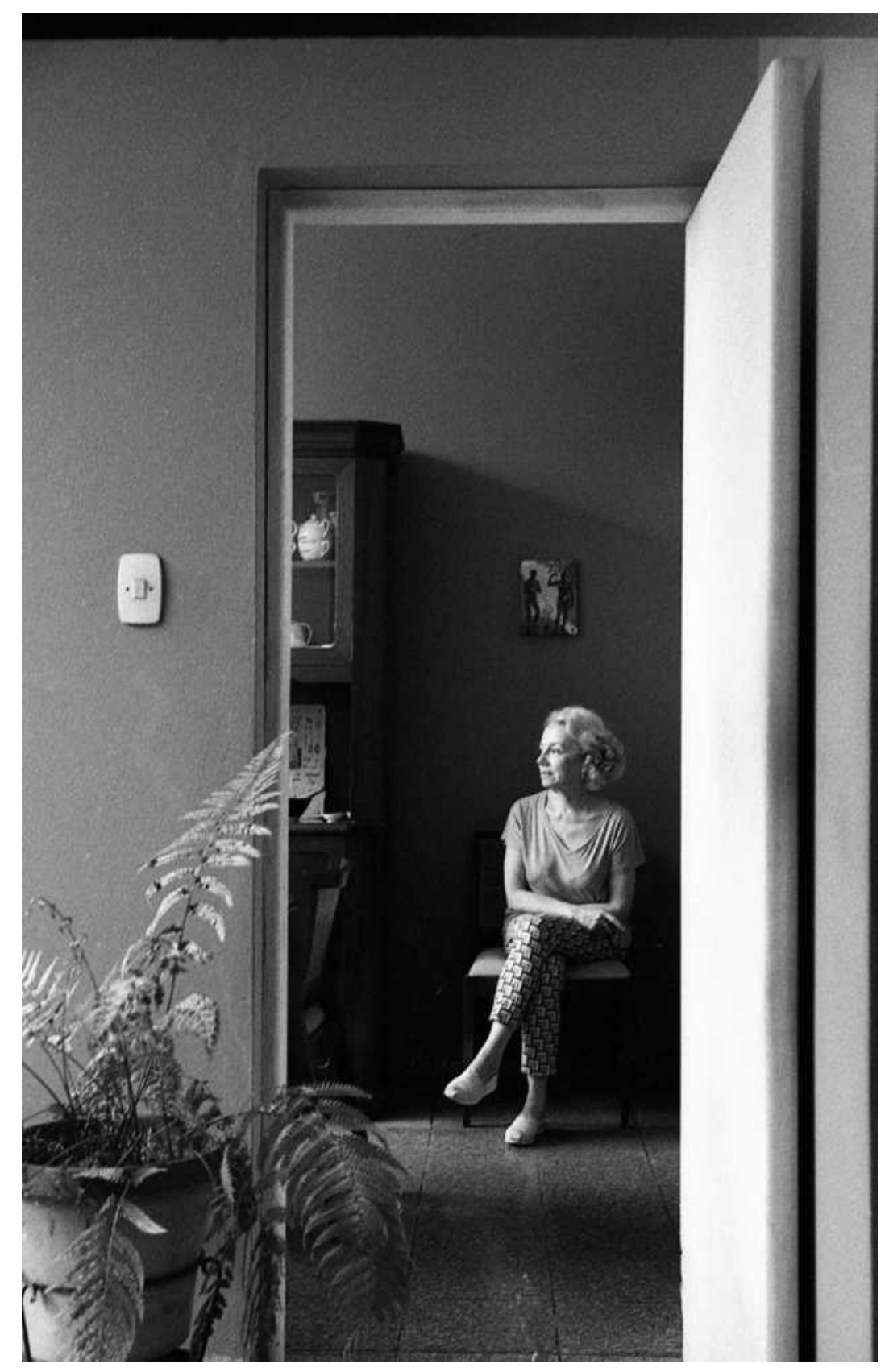

Ana María Gazzolo 


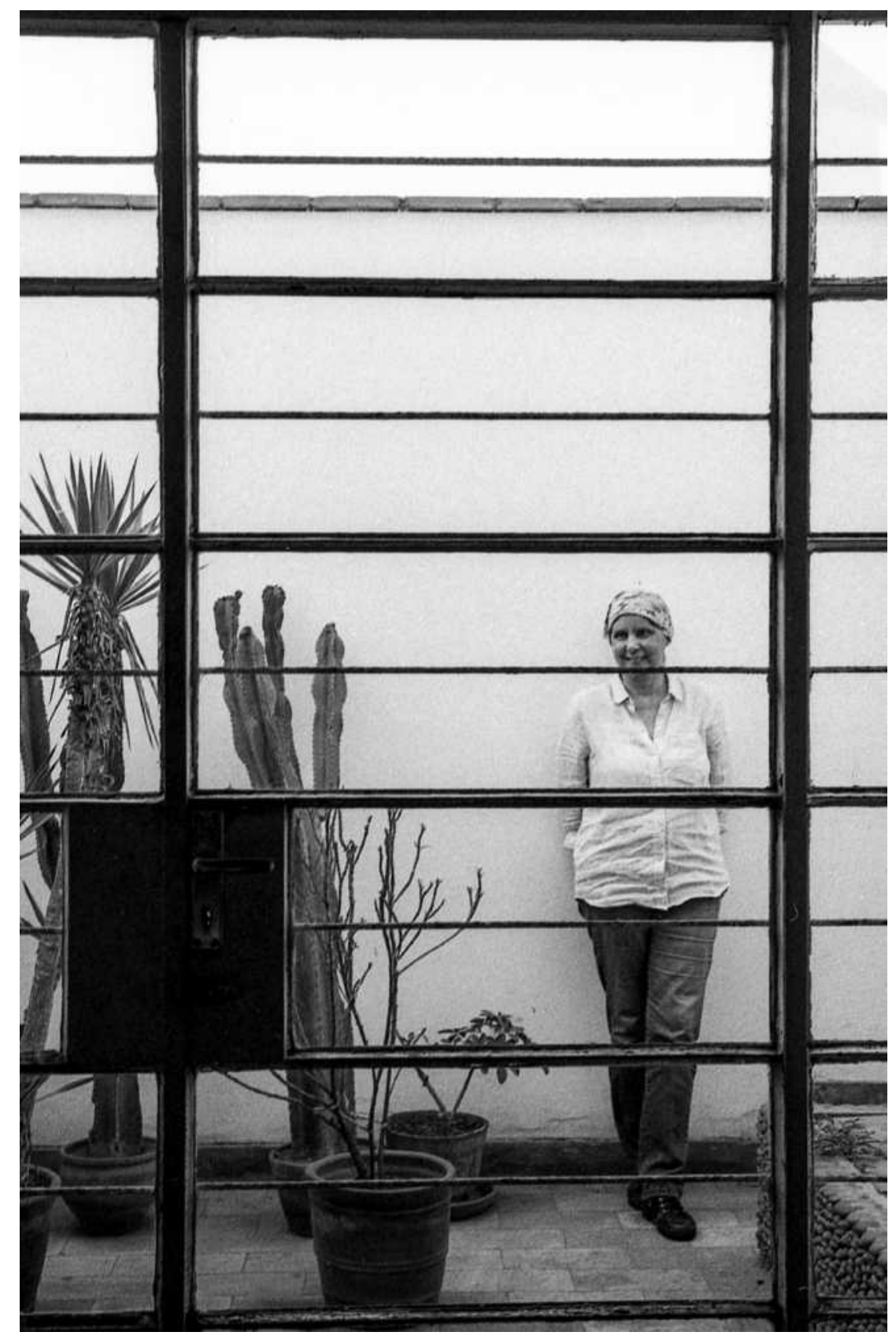

Rossela Di Paolo 


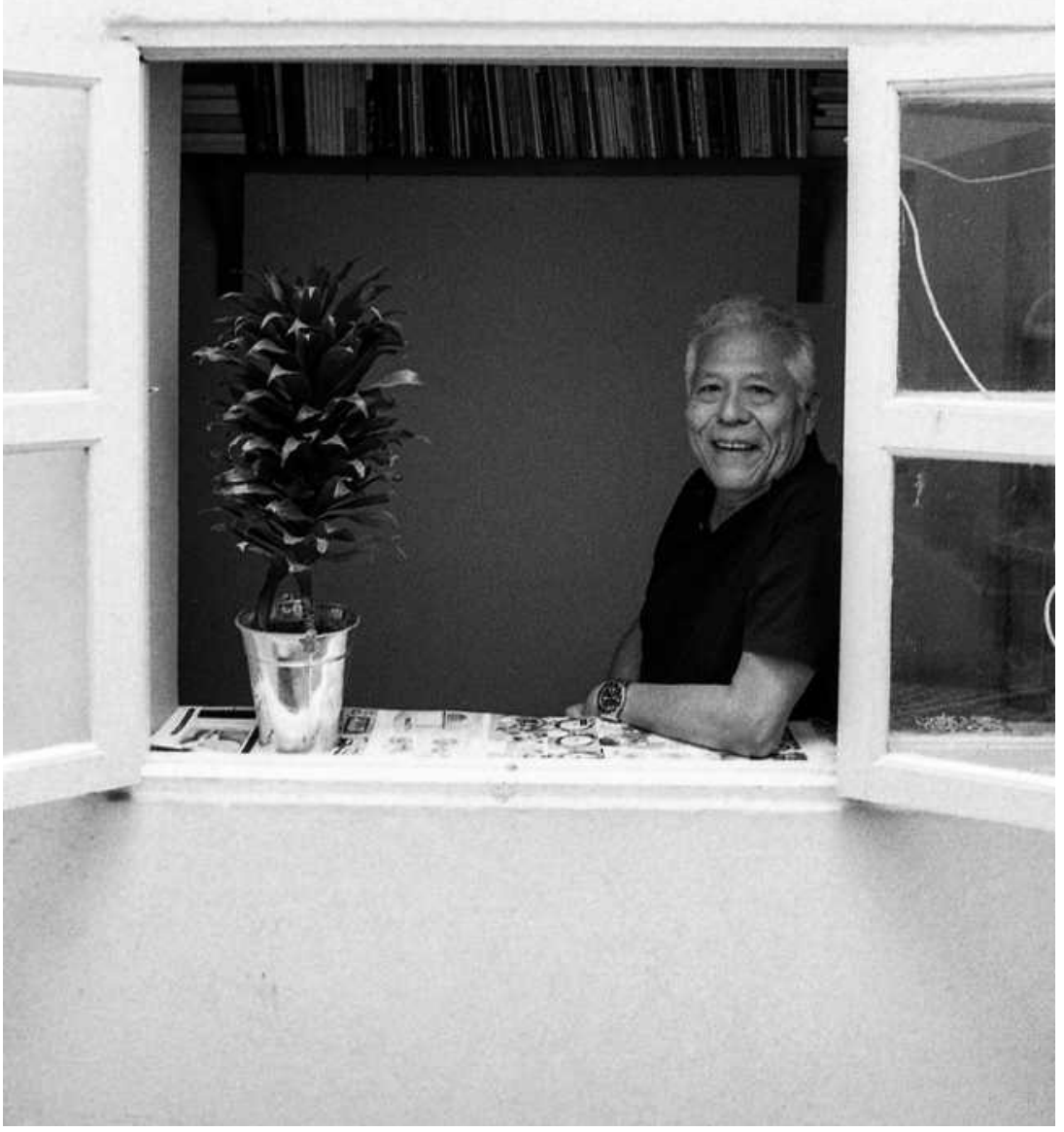

Enrique Sánchez Hernani 


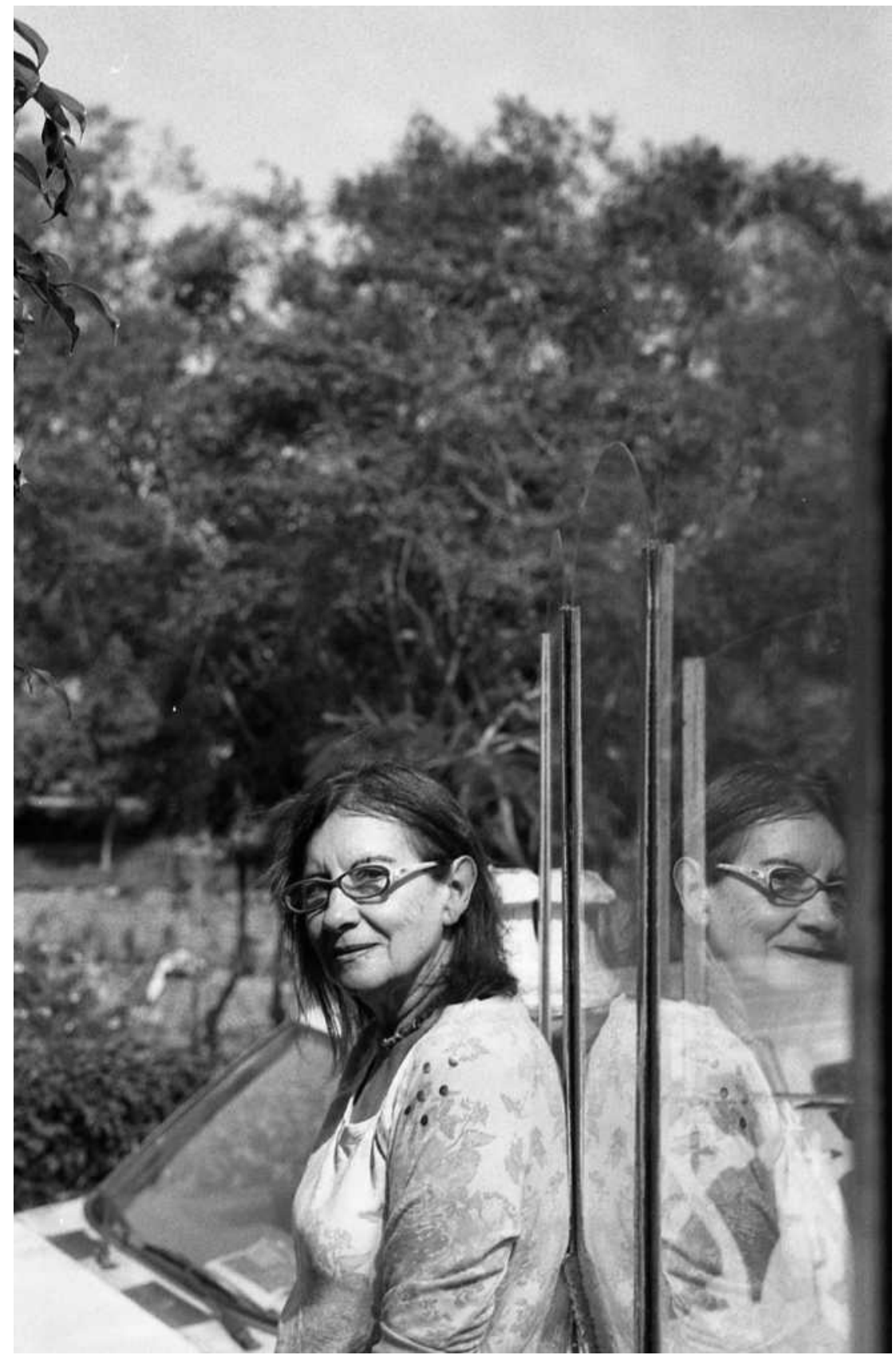

Carmen Ollé 


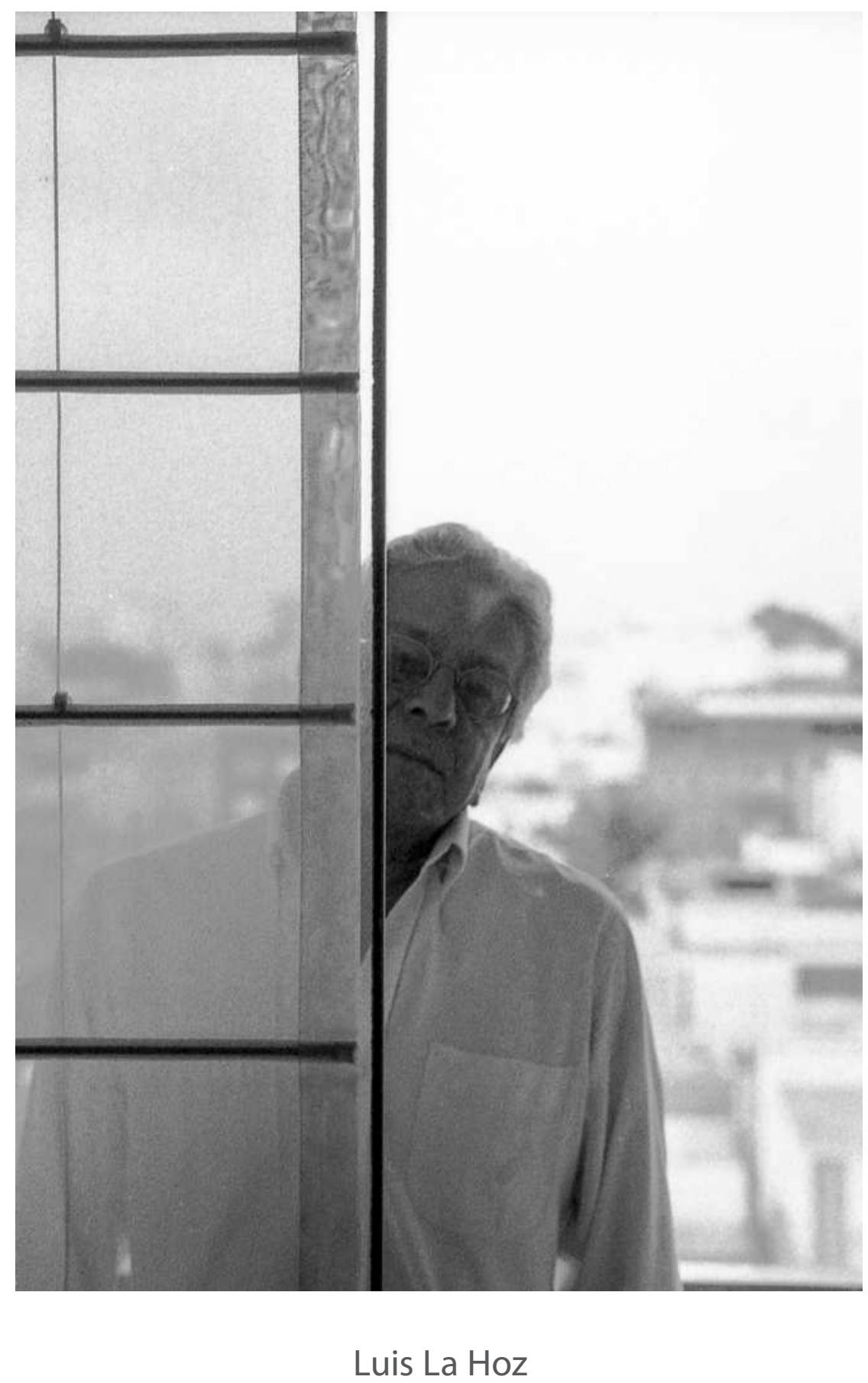




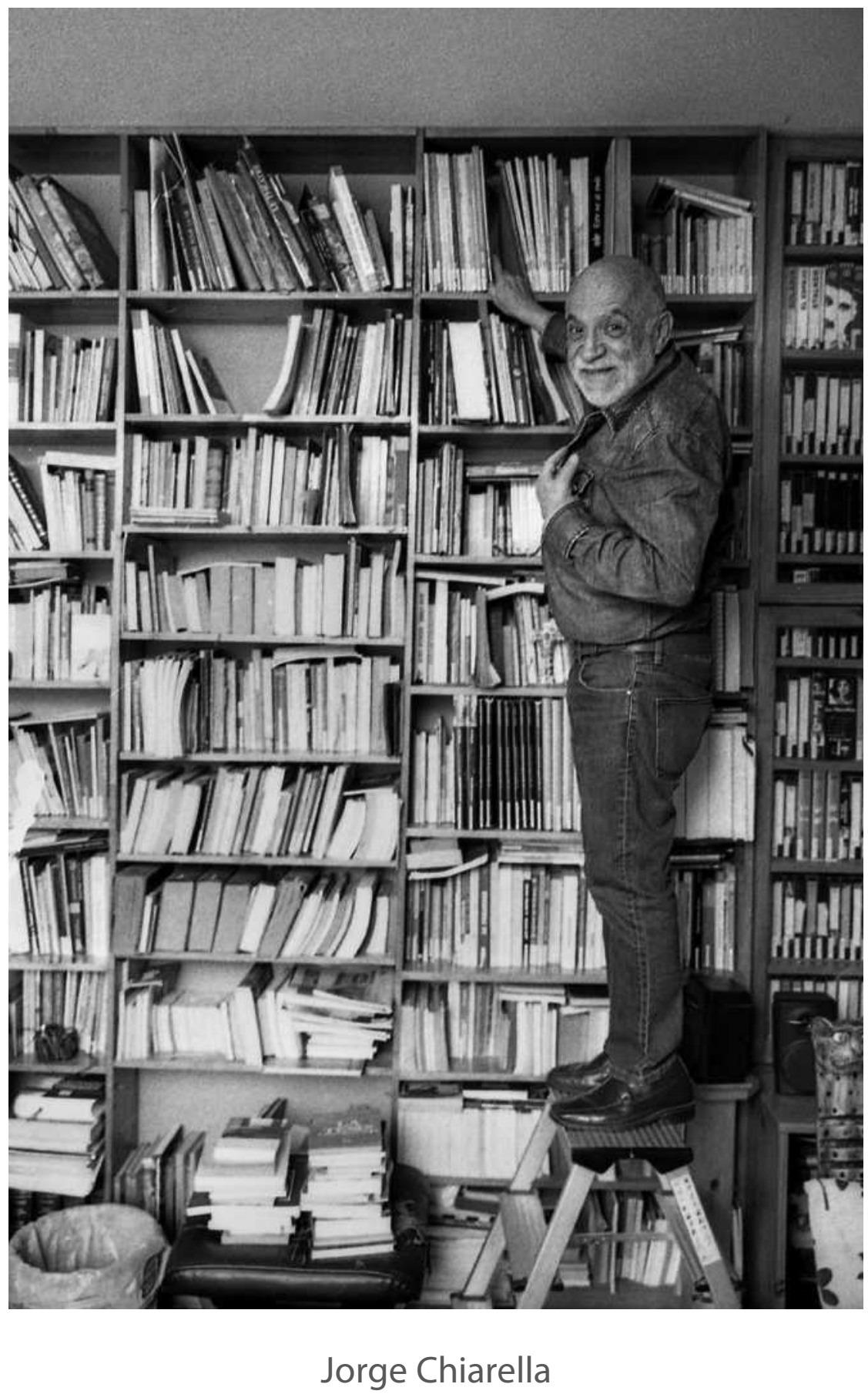




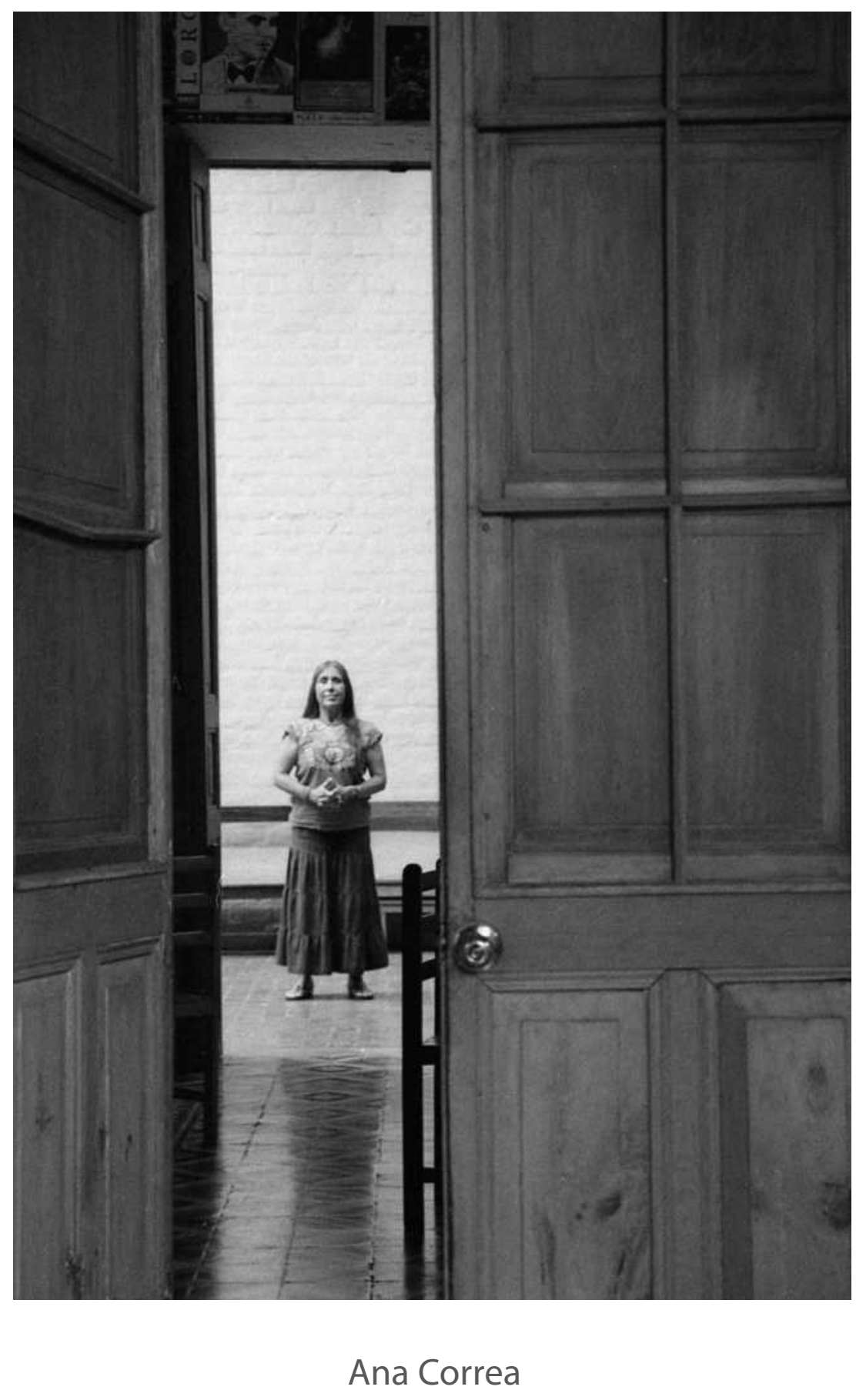




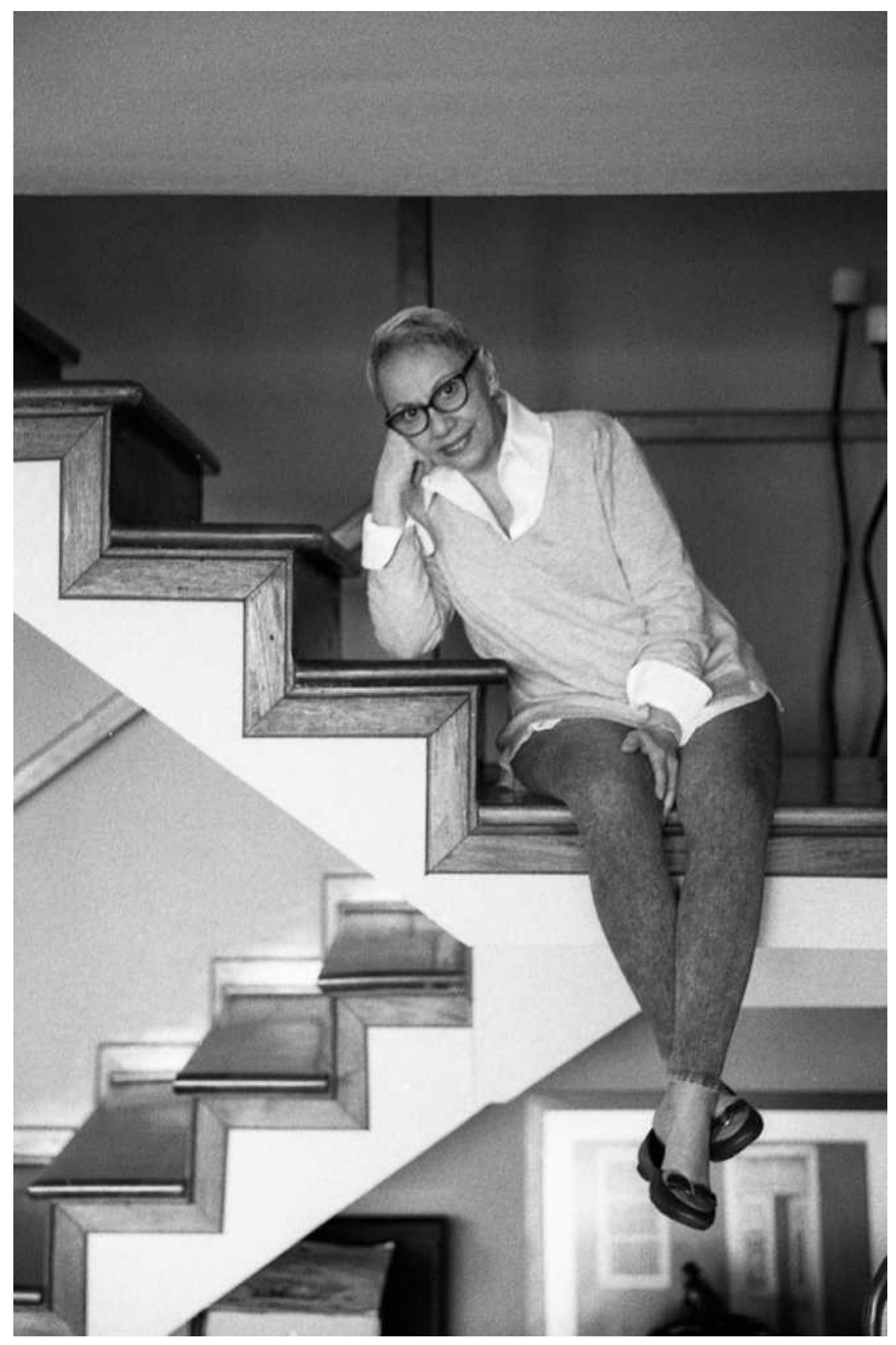

Celeste Viale 


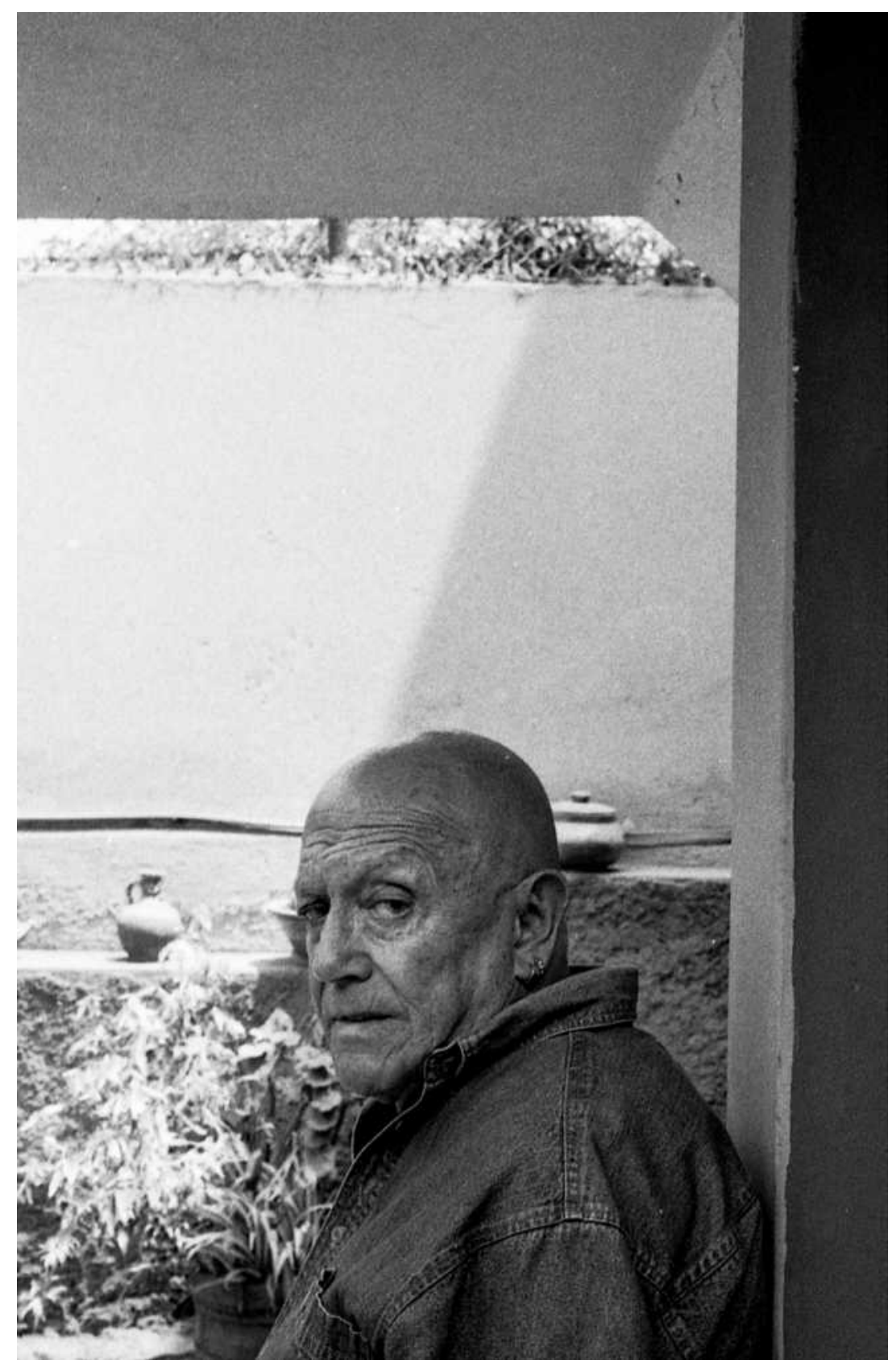

Édgar Guillén 


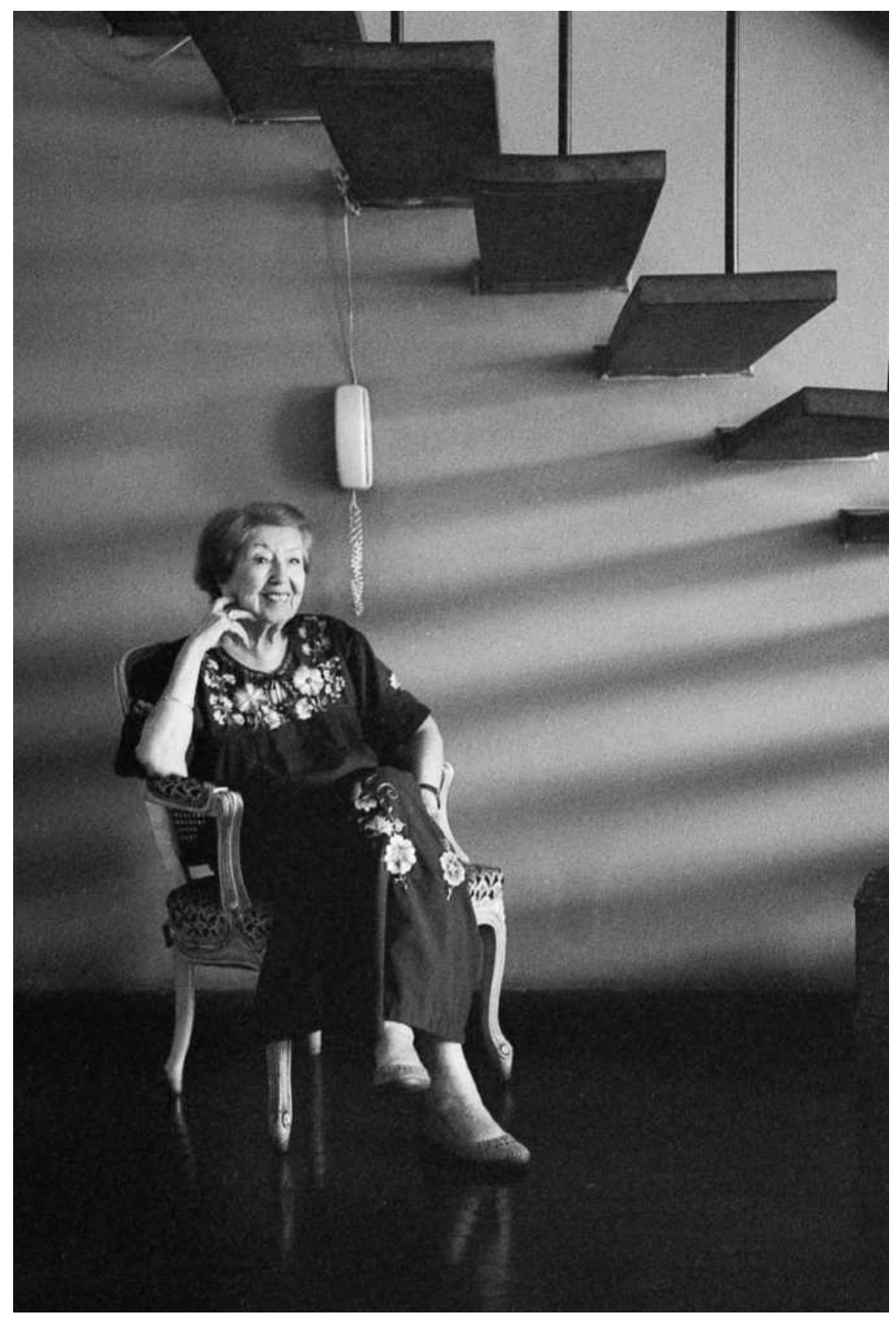

Sonia Seminario 


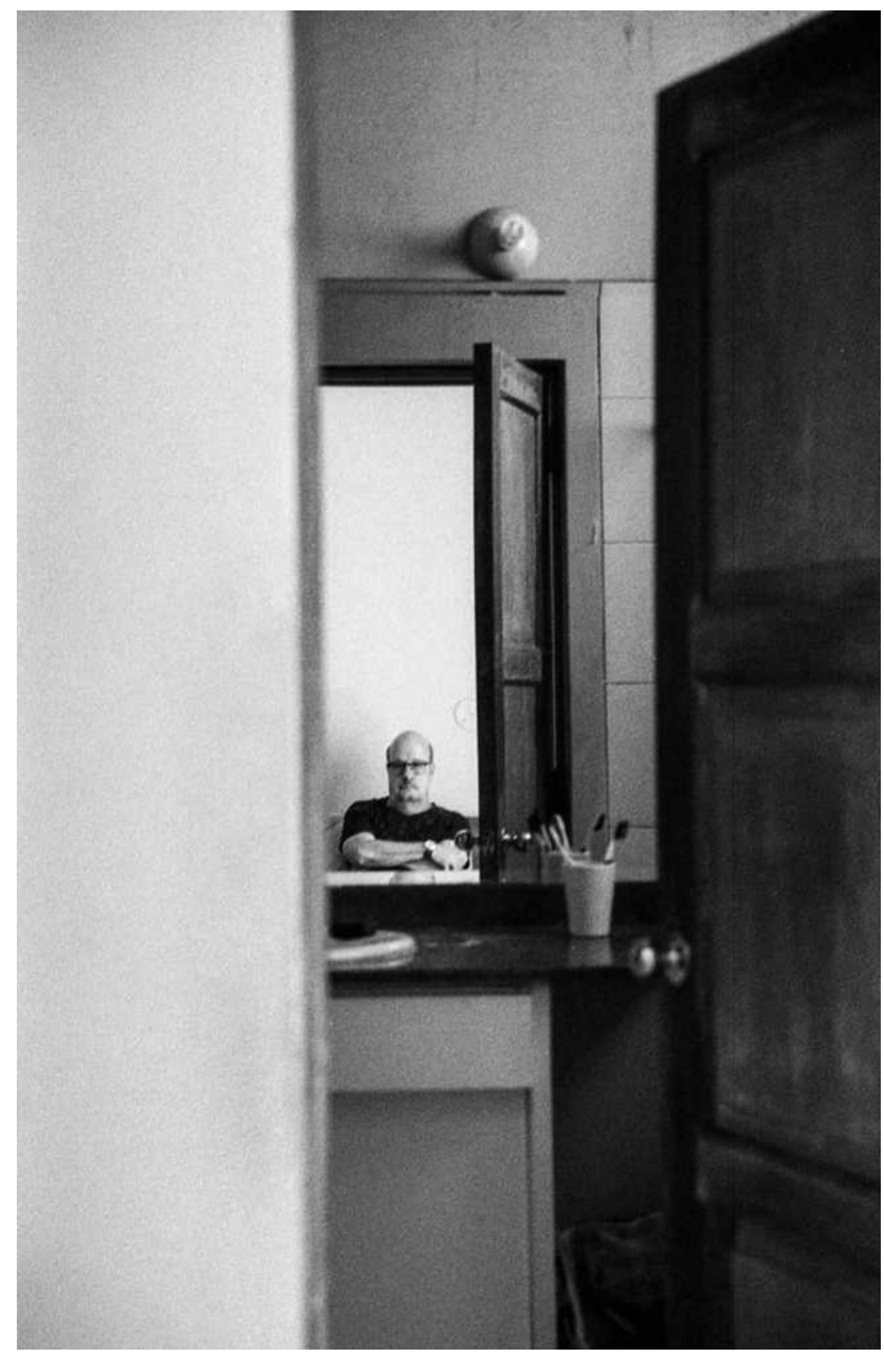

Alfonso Santistevan 


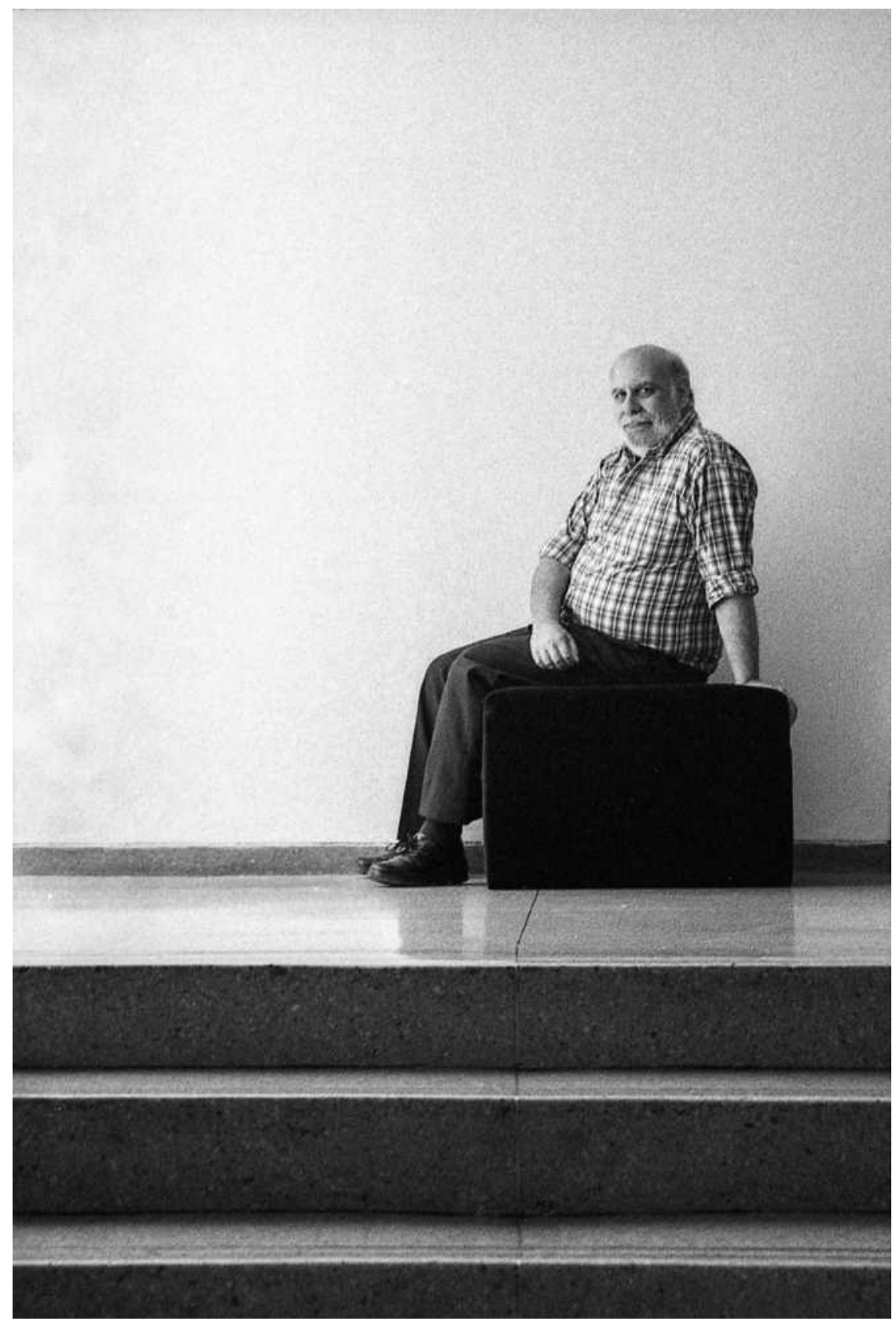

Alberto Ísola 

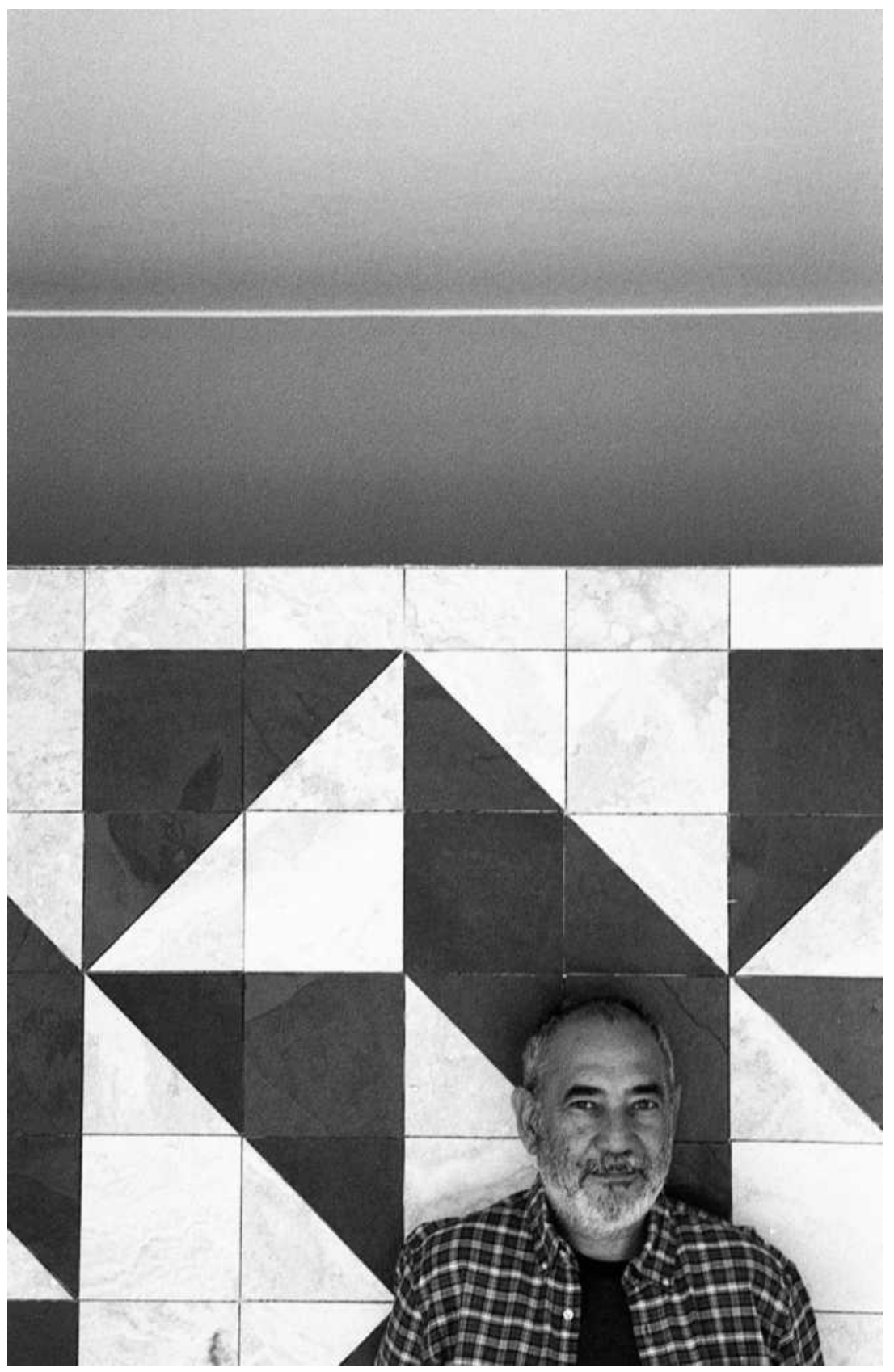

César De María 
